J Vasc Surg Venous Lymphat Disord. 2018 July ; 6(4): 464-470. doi:10.1016/j.jvsv.2018.02.008.

\title{
Clinical Outcomes After Varicose Vein Procedures in Octogenarians within the Vascular Quality Initiative Varicose Vein Registry
}

\author{
Danielle C. Sutzko, MD, MS, Andrea T. Obi, MD, Andrew S. Kimball, MD, Margaret E. Smith, \\ MD, Thomas W. Wakefield, MD, and Nicholas H. Osborne, MD, MS \\ Section of Vascular Surgery, University of Michigan Medical School
}

\begin{abstract}
Background-While Chronic Venous Insufficiency (CVI) and Varicose Veins (VVs) are a universally recognized problem, they are frequently under-appreciated as major contributors to long-term morbidity in the elderly despite the increasing prevalence with age. Prior studies have demonstrated that CVI and VV treatments in patients $\geq 65$ yield an overall benefit, however, there has been little data if octogenarians are undergoing these procedures and with what success. As such, our objectives were to (1) investigate the procedures selected, (2) examine clinical outcomes following VV procedures in elderly patients $\geq 80$ years old and (3) explore complication rates (both systemic and leg specific) following VV procedures in patients $\geq 80$ years old.

Methods-We performed a retrospective review using the Vascular Quality Initiative Varicose Vein Registry (VQI VVR) of all VV procedures performed for $\geq \mathrm{C} 2$ disease from January $2015-$ February 2017. We divided all procedures into three age groups: patients $<65$, patients $\geq 65-79$, and patients $\geq 80$ years of age. Statistical testing included Chi squared test for categorical variables and student $t$ test for continuous variables. Two comparisons were performed. First comparing patients $<65$ to $\geq 65-79$ and second, comparing patients $\geq 65-79$ to $\geq 80$.
\end{abstract}

Results-There were a total of 12,262 procedures performed with 8,608 procedures in the $<65$ group, 3,226 in the 65-79 group, and 428 procedures in patients $\geq 80$ years old. A total of 22,050 veins were treated during the 12,262 procedures. Almost half of procedures $(46.51 \%, \mathrm{~N}=5,703)$ had only one vein treated during a single procedure. Between age groups, the percentage of one vein treated increased as patient age increased, ranging from $45.39 \%(\mathrm{~N}=3,875)$ for patients $<65$, $48.55 \%(\mathrm{~N}=1,555)$ for patients between $65-79$, to $64.08 \%(\mathrm{~N}=273)$ for patients $\geq 80$. Patients in the $\geq 80$ group had an overall lower average BMI, were more likely to be on anticoagulation and undergo truncal procedures alone compared to the other groups. The $\geq 80$ group had a significant

Corresponding author: Danielle C. Sutzko, MD, MS, University of Michigan Health System, 1500 E. Medical Center Drive, Frankel Cardiovascular Center, Ann Arbor, MI 48109-5867, horned@med.umich.edu, Phone: (734) 763-0250, FAX: (734) 647-9867.

Publisher's Disclaimer: This is a PDF file of an unedited manuscript that has been accepted for publication. As a service to our customers we are providing this early version of the manuscript. The manuscript will undergo copyediting, typesetting, and review of the resulting proof before it is published in its final citable form. Please note that during the production process errors may be discovered which could affect the content, and all legal disclaimers that apply to the journal pertain.

Presented in part at the $41^{\text {st }}$ Annual Midwestern Vascular Surgical Society Meeting, Chicago, IL, September 8, 2017. Recipient of the John R. Pfeifer Award for the best venous paper.

Conflicts of Interest: None 
improvement in both venous clinical severity scores (VCSS) $(4.37 \pm 4.16, \mathrm{p}<.001)$ and patient reported outcomes (PROs) $(8.79 \pm 7.27, \mathrm{p}<.001)$ from pre to post procedure. Overall complications were low in all age groups. The octogenarians had no higher risk of systemic complications.

Conclusions-Vascular specialists are performing VV procedures in octogenarians and are more likely to perform truncal only therapy. Additionally, octogenarians have statistically significant improvement of VCSS and PROs with a low risk of complications despite more advanced venous disease at presentation.

\section{Keywords}

Vascular Quality Initiative Varicose Vein Registry (VQI VVR); Varicose veins; Clinical; Etiology; Anatomy and Pathophysiology (CEAP); Venous clinical severity score (VCSS); Patient reported outcomes (PROs); Octogenarian

\section{Introduction}

Varicose veins are a common problem that can have profound effects on patient quality of life. ${ }^{1}$ Known risk factors include advancing age, obesity and female gender. ${ }^{2-5}$ Many propose conservative management with compression hose; however strong evidence that this alone is sufficient is lacking. Furthermore, patients have a high rate of intolerance with this therapy. ${ }^{6}$ Varicose vein procedures have the ability to decrease the severity of venous disease and decrease patient morbidity while remaining cost-effective. ${ }^{7-9}$

The Vascular Quality Initiative (VQI) Varicose Vein Registry (VVR) is a quality collaborative that began in January 2015 to capture varicose vein procedures performed across the United States. The VQI VVR has been shown to be useful in monitoring changes after varicose vein treatment. Data from the VQI VVR has established that modern day varicose vein surgery yields substantial improvements in venous clinical severity scores (VCSS) and patient reported outcomes (PROs). ${ }^{10}$ These improvements remain, even in the Medicare population. ${ }^{11}$ Although these studies have demonstrated a benefit with overall low complication rates, patients' $\geq 80$ or octogenarians have yet to be examined despite advanced age being a known risk factor for varicose veins. In addition, current clinical practice guidelines, as outlined by the American Venous Forum, do not specify treatment for patients who present with chronic venous insufficiency and varicose veins at advanced ages. 7

Using the VQI VVR data, we sought to (1) investigate the procedures selected, (2) examine clinical outcomes including the $\mathrm{C}$ class of the clinical etiology anatomic physiologic (CEAP) classification, VCSS, and PROs as well as (3) explore complication rates (both systemic and leg specific) following VV procedures in elderly patients $\geq 80$ years old. 


\section{Methods}

\section{Data source and data capture}

All varicose vein procedures in the VQI VVR were examined. Details on this registry have been previously explained. ${ }^{10,11}$ In short, the VQI VVR is a quality collaborative that falls under the Society for Vascular Surgery Patient Safety Organization (SVS PSO) which was approved in February 2011 by the Agency for Healthcare Research \& Quality (AHRQ) to improve patient safety and quality of care while protecting data sharing between participating partners. This dataset prospectively captures all varicose vein procedures performed at participating centers (currently 27) for $\geq \mathrm{C} 2$ or greater disease. Access to the VQI VVR is granted through a regional and national application process that includes concomitant institutional review board (IRB) approval (HUM00114502). All patient information in the dataset is de-identified and use of this information does not require informed consent.

\section{Procedure selection}

For our study, procedures from 2014 were excluded as these were entered into the registry retrospectively and procedures after February 2017 were also excluded to ensure patients had adequate time for follow up. Following these exclusions, all procedures were divided into three age groups: procedures performed in patients $<65$ years of age, $\geq 65$ to 79 and $\geq$ 80 years of age. Of note, all patients between 79 and 80 years of age were considered 79 and included in the middle age group for analysis. To determine the types of procedures selected, all procedures were divided into either treatment of axial reflux or truncal procedures, treatment of varicose veins or cluster procedures, or perforator procedures. We also examined various combinations of these procedures.

\section{Clinical Outcomes}

Clinical outcomes included the $\mathrm{C}$ class of the CEAP classification, specifically looking at CEAP class improvement, which we defined as moving from a higher $\mathrm{C}$ class to a lower $\mathrm{C}$ class, VCSS and PROs score improvement and systemic and leg specific complication rates. Trained clinical data abstractors at each center prospectively record outcomes in the VQI VVR both pre procedurally and after the procedure during the two follow up time points, early (0-3 months) and late ( $>3$ months). The $\mathrm{C}$ class of the CEAP classification were recorded pre and postoperatively. Of note, when patients are $\mathrm{C} 5$, they cannot be designated below a C5. VCSS and PRO scores were also collected both pre and postoperatively. VCSS includes 10 different components scored from 0-3 for a total component score ranging from 0-30: presence of varicose veins, edema, pigmentation, inflammation, induration, active ulcers, ulcer duration, ulcer size, compression therapy and pain. PRO includes 7 different subjective components scored from 0-5 for a total component score 0-35: heaviness, achiness, throbbing, swelling, itching, appearance and impact on work. For both VCSS and PROs, the component scores were compared pre to post procedure. Systemic complications recorded in the VQI VVR include mild and severe allergic reactions, migraine, visual disturbance, cough/chest tightness, systemic infection, pulmonary embolism (PE), transient ischemic attach (TIA), stroke, and death. Systemic complications were recorded at the time of the procedure, while the leg specific complications were recorded during the follow up 
appointment and included bleeding, blistering, deep venous thrombosis (DVT), hematoma, paresthesia, pigmentation, superficial phlebitis, treatment induced ulcer, wound infection and endovenous heat induced thrombus (EHIT). All clinical outcomes were first compared between the $<65$ year old group and the 65-79 age group. Next the patients 65-79 years of age were compared to octogenarian patients. We did not compare the octogenarian group to the patients $<65$, as we previously established in an earlier analysis that the Medicare population benefit from these procedures. ${ }^{11}$

\section{Statistical analysis}

To evaluate baseline demographics and patient characteristics, univariate analysis was completed for all patients that underwent a single procedure to account for duplicates, as this is a dataset of procedures. For the statistical analysis, $X^{2}$ was used for comparison of categorical variables and student t-test was used for continuous variables as they were normally distributed. A p value of $<.05$ was considered statistically significant. The analysis was completed using Stata 14.0 software (StataCorp LP, College Station, TX).

\section{Results}

\section{Patient characteristics and clinical presentation}

A total of 13,679 varicose vein procedures were in the VQI VVR dataset on initial analysis, however we excluded 107 procedures from 2014 since these were entered retrospectively and 1,310 procedures after February 2017 to ensure adequate time for follow up. After exclusions, 12,262 procedures remained. There was a total of 8,608 procedures performed in 4,043 patients $<65$ years of age (average age $48.30 \pm 10.62$ ), 3,226 procedures in 1,334 patients between ages $65-79$ (average age $70.43 \pm 4.08$ ) and 428 procedures performed in 161 octogenarians (average age $83.29 \pm 2.87$ ) [Figure 1].

Table I summarizes patient baseline demographics and patient history between the three age groups. The 65-79 year old group had a higher percentage of white patients (79\% vs. 72\%, p $=.001)$, patients with a history of previous varicose vein treatment (31\% vs. $28 \%, \mathrm{p}=.047)$, deep vein thrombosis $(8 \%$ vs. $5 \%, \mathrm{p}<.001)$ and on anticoagulation therapy $(14 \%$ vs. $5 \%$, p $<.001$ ) when compared to the patients $<65$. The octogenarian group had similar characteristics when compared to the 65-79 group with the exception of having a lower average BMI $(22.25 \pm 4.91$ vs. $29.11 \pm 6.21, \mathrm{p}<.001)$ and the highest percentage of patients on anticoagulation ( $20 \%$ vs. $14 \%, \mathrm{p}=.029)$.

\section{Anatomic and Procedure Breakdown}

When examining procedure breakdown, the most common procedures for all age groups was isolated truncal procedures, followed by combined truncal and cluster treatment.

Interestingly, when we examined the number of veins per procedure treated between age groups, the percentage of procedures treating only one vein increased as patient age increased, ranging from $45 \%(\mathrm{~N}=3,875)$ of procedures for patients $<65,48 \%(\mathrm{~N}=1,555)$ of procedures for patients between $65-79$, to $64 \%(\mathrm{~N}=273)$ of procedures for patients $\geq 80$ (Figure 1). 


\section{Outcomes}

Figure 2 depicts the numbers of procedures performed for each pre procedure CEAP class stratified by age group. C3 was the most common presentation for both patients < 65 $(\mathrm{N}=3,350,39 \%)$ and patients $65-79(\mathrm{~N}=1,060,33 \%)$, whereas the octogenarian patients were more likely to present with $\mathrm{C} 4 \mathrm{a}(\mathrm{N}=113,26 \%)$. In octogenarians, the majority of procedures were initiated for $\mathrm{C} 4 \mathrm{a}(\mathrm{N}=113,26.40)$ or $\mathrm{C} 6$ with an active ulcer $(\mathrm{N}=87,20 \%)$. There were only 15 procedures $(3.50 \%)$ performed on octogenarians with C5 disease. All three age groups had a significant improvement in CEAP from pre to post procedure (Figure 3A-C). For patients $<65$ years old, the number of patients in $\mathrm{C} 0$ and $\mathrm{C} 1$ class increased after treatment (C0 from 49 to 709 ) and $\mathrm{C} 1$ (47 to 1375), while those in C2 (1761 to 1149), C3 (1988 to 1014), C4a (811 to 548), C4b (176 to 129) and C6 (226 to 117) all decreased. For patients 65-79 years of age, we saw similar trends with $\mathrm{C} 0-1$ class increasing following treatment ( $\mathrm{C} 0$ from 26 to 219; $\mathrm{C} 1$ from 5 to 446) and $\mathrm{C} 2, \mathrm{C} 3, \mathrm{C} 4 \mathrm{a}, \mathrm{C} 4 \mathrm{~b}$ and $\mathrm{C} 6$ decreasing following treatment $\mathrm{C} 2$ (566 to 506), (C3 from 693 to 422), C4a (542 to 343), C4b (124 to 88), C6 (107 to 52). Finally, in the octogenarian group we found the same findings with $\mathrm{C} 0-2$ class increasing following treatment ( $\mathrm{C} 0$ from 2 to 17 ), $\mathrm{C} 1$ (4 to 40), $\mathrm{C} 2$ (39 to 54) and $\mathrm{C} 3, \mathrm{C} 4 \mathrm{a}, \mathrm{C} 4 \mathrm{~b}$ and $\mathrm{C} 6$ decreasing following treatment (C3 from 81 to 45 ), $\mathrm{C} 4 \mathrm{a}$ (70 to 62), $\mathrm{C} 4 \mathrm{~b}$ (18 to 12), C6 (53 to 27). With regards to octogenarians with active ulceration or $\mathrm{C} 6$ disease, $55 \%$ of procedures $(\mathrm{N}=29)$ with post procedure follow-up resulted in a healed ulcer.

VCSS and PRO component scores improved for all age groups pre to post procedure (Table II). For VCSS, patients $<65$ had a pre procedure mean of $7.98 \pm 3.56$ (95\% CI 7.88-8.08), a post procedure mean of $3.84 \pm 3.71$ (95\% CI 3.74-3.95) with an overall difference of 4.14 $\pm 3.47(95 \%$ CI $4.04-4.23, \mathrm{p}<.001)$. The patients $65-79$ had a pre procedure mean of 8.42 \pm 3.86 (95\% CI 8.25-8.58), a post procedure mean of $4.35 \pm 3.98$ (95\% CI 4.18-4.52) with an overall difference of $4.07 \pm 3.76$ (95\% CI 3.91-4.23, $\mathrm{p}<.001)$. The octogenarian group had a pre procedure mean of $10.23 \pm 5.03$ (95\% CI 9.63-10.83), a post procedure mean 5.86 \pm 4.95 (CI 5.27-6.45) with an overall difference of $4.37 \pm 4.16$ (95\% CI 3.87-4.86, $\mathrm{p}<.001$ ). For PRO, patients < 65 had a pre procedure mean of $15.18 \pm 6.71$ (95\% CI 14.98-15.38), a post procedure mean of $4.62 \pm 5.58$ (95\% CI 4.46-4.79) with an overall difference of 10.56 \pm 7.42 (95\% CI 10.34-10.78, $\mathrm{p}<.001$ ). The patients $65-79$ had a pre procedure mean of $14.09 \pm 6.60$ (95\% CI 13.80-14.39), a post procedure mean of $4.46 \pm 5.45$ (95\% CI 4.22-4.71) with an overall difference of $9.63 \pm 7.00$ (95\% CI 9.32-9.94, $\mathrm{p}<.001)$. The octogenarian group had a pre procedure mean of $14.44 \pm 7.45$ (95\% CI 13.50-15.37), a post procedure mean $5.65 \pm 6.51$ (95\% CI 4.83-6.46) with an overall difference of $8.79 \pm 7.27$ (CI 7.88-9.70, $\mathrm{p}<.001)[$ Table II].

When comparing mean improvement of VCSS between patients $<65$ vs. 65-79 (4.14 vs. $4.07, \mathrm{p}=.446$ ) and between the two older age groups (4.07 vs. $4.37, \mathrm{p}=.217$ ) there was no difference. However there was a statistically significant difference between the mean PRO improvement between patients < 65 vs. $65-79$ (10.56 vs. 9.63, p < .001). When comparing the overall mean PRO improvement between patients 65-79 vs. the octogenarian group there was no difference (9.63 vs. $8.79, \mathrm{p}=.078$ ). 


\section{Complications}

The overall leg complication rate was $6.65 \%(\mathrm{~N}=419)$, ranging from $5.71 \%(\mathrm{~N}=12)$ in the octogenarian group to $6.73 \%(\mathrm{~N}=296)$ in the $<65$ year old group. The overall rate of systemic complications was $0.44 \%(\mathrm{~N}=54)$, ranging from $0.43-0.70 \%$. Of note, the octogenarian group had similar rates in both of these categories compared to the other patient cohorts (Table I). Overall follow up in our cohort was 75\%.

\section{Discussion}

Within the VQI VVR, octogenarians undergoing varicose vein procedures predominantly have isolated venous procedures and typically have a truncal alone procedure. We also discovered that octogenarians undergoing varicose vein procedures are more likely to have advanced disease, with $56 \%$ of procedures performed for $\geq \mathrm{C} 4 \mathrm{a}$ disease. Despite advanced age and more severe venous disease, octogenarians had a statistically significant improvement in VCSS and PROs with an overall low complication rate that was similar to other age groups.

There is a paucity of data regarding treatment of varicose veins in the elderly. Importantly, our study demonstrates that varicose vein disease in octogenarians is often first treated by vascular specialists at more advanced disease stages than their younger counterparts. This suggests that specialists may be more selective in intervening on elderly patients, pursuing conservative treatment more frequently for elderly patients than younger patients. This may also reflect a general reluctance to refer octogenarians to specialists until they are experiencing venous wounds. The VQI VVR is a procedural database and does not capture the full denominator of patients referred to vascular specialists, thus it is impossible to know how many octogenarian patients were seen and not offered an intervention either for prohibitive comorbidity burden or because proceduralists were not willing to intervene for less severe disease.

Importantly, despite more severe disease, it appears that octogenarians do benefit from the procedures offered. A recent study by Pappas et al also found a higher incidence of skin changes and ulceration with good treatment improvement. ${ }^{12}$ The patients who undergo surgery do benefit, with $55 \%$ of ulcers healed following treatment in our cohort. This healing rate is similar to healing rates seen by others ${ }^{13,14}$, such as Marston et al after 10 weeks of compression and wound therapy. In this study, the average cost for 10 weeks of outpatient therapy was $\$ 2198 \pm \$ 445 .{ }^{15}$ The 10 -week outpatient compression therapy included at least weekly dressing changes with a return visit to clinic every 1-3 weeks depending on need for home nursing visits. Given this result, the argument can be made that ulcer healing can be achieved with just compression, however when examining a study by Lin et al, the cost of office based interventional procedures was less expensive than compression seen in the previous study. In this retrospective analysis of the professional and technical portions for the charges and costs of RFA and/or EVLT at a tertiary care hospital in Detroit, MI ranged between $\$ 1074$ and \$1534 in the years 2010 and 2011. ${ }^{16}$ This suggests that performing these procedures are helping ulcer healing with less cost to the system. 
Our study revealed overall improvement in VCSS and PROs from pre to post procedure measurements in octogenarians. This suggests not only objective improvement in venous disease, but also in patient reported symptoms of heaviness, achiness, swelling, throbbing, itching and appearance. This is important given the overall emphasis on quality of life and patient reported outcomes in modern medicine as quality of life becomes as important of an outcome as the traditional measures of surgical outcomes, recurrence rates and complications. In addition to venous disease quality of life measures in vascular surgery ${ }^{17-19}$, there have been quite a few specialties that have specifically looked at QOL. 20-22 McGirt et al compared effectiveness, morbidity and quality of life following lumbar surgery in the elderly (70 years of age and older) compared to patients younger than 70 years of age. They found that the elderly had significant and equivalent improvements at 1 year in pain, disability and quality of life in both groups. These authors also found surgical complications to be similar among both the young and older patient cohort. ${ }^{23}$

Overall complication rates in our study were similarly low for all age groups. The octogenarians did not have a higher complication rate, despite having more advanced venous disease. In the same study by McGirt et al examining lumbar surgery in the elderly patients ( $\geq 70$ years of age) compared to younger patients ( $<70$ years of age), both patient cohorts also had similar complication rates. ${ }^{23}$ This study highlights a disease process that is increased in the elderly with potential for surgical intervention to have substantial improvements of patient quality of life and suggest that vascular specialists currently treating octogenarians can be encouraged to continue their current practices. They may even consider intervening earlier when necessary given the low risk of morbidity and mortality in this population. Those specialists that are hesitant can be reassured that with good patient selection, procedures can be performed which provides benefit to the patient without high complications.

\section{Limitations}

Our study has a few important limitations. First, this a retrospective review of the prospectively collected VQI VVR. Secondly, the follow up in our study was only $75 \%$, however this is much improved compared to our previous investigations conducted with the VQI VVR (45\% and 62.2\%). ${ }^{10,11}$ Third, selection bias cannot be excluded or fully adjusted for given the database is a procedural dataset which collects pre and post procedural data only patients undergoing varicose vein procedures. This fails to capture all the patients that may have been seen in clinic and been denied treatment for various reasons. Finally, some of the outcomes included in the PROs are subjective and thus have the potential for response bias.

\section{Conclusion}

Vascular specialists are performing VV procedures in octogenarians and are more likely to perform truncal only treatment. Importantly, this patient population presents for treatment with more severe disease, with $20 \%$ of this cohort has active ulceration at presentation with approximately 55\% healing after therapy. Additionally, octogenarians have statistically significant improvement of VCSS and PROs with a low risk of complications. Taken 
together, these findings suggest that VV procedures are safe and effective in the appropriately selected elderly patient.

\section{References}

1. Beebe-Dimmer JL, Pfeifer JR, Engle JS, Schottenfeld D. The epidemiology of chronic venous insufficiency and varicose veins. Ann Epidemiol. 2005 Mar; 15(3):175-84. [PubMed: 15723761]

2. Suehiro K, Morikage N, Yamashita O, Harada T, Samura M, Takeuchi Y, et al. Risk Factors in Patients with Venous Stasis-Related Skin Lesions without Major Abnormalities on Duplex Ultrasonography. Ann Vasc Dis. 2016; 9(3):201-4. [PubMed: 27738462]

3. Musil D, Kaletova M, Herman J. Age, body mass index and severity of primary chronic venous disease. Biomed Pap Med Fac Univ Palacky Olomouc Czech Repub. 2011 Dec; 155(4):367-71. [PubMed: 22336650]

4. Bozkurt AK, Balkanay OO. Approach to venous diseases in the elderly. Turk Kardiyol Dern Ars. 2017 Sep; 45(Suppl 5):102-7.

5. Maurins U, Hoffmann BH, Losch C, Jockel K-H, Rabe E, Pannier F. Distribution and prevalence of reflux in the superficial and deep venous system in the general population-results from the Bonn Vein Study, Germany. J Vasc Surg. 2008 Sep; 48(3):680-7. [PubMed: 18586443]

6. Nelson EA, Bell-Syer SEM. Compression for preventing recurrence of venous ulcers. Cochrane database Syst Rev. 2014 Sep.(9):CD002303. [PubMed: 25203307]

7. Gloviczki P, Comerota AJ, Dalsing MC, Eklof BG, Gillespie DL, Gloviczki ML, et al. The care of patients with varicose veins and associated chronic venous diseases: clinical practice guidelines of the Society for Vascular Surgery and the American Venous Forum. J Vasc Surg. 2011 May; 53(5 Suppl):2S-48S. [PubMed: 21536172]

8. Brittenden J, Cotton SC, Elders A, Tassie E, Scotland G, Ramsay CR, et al. Clinical effectiveness and cost-effectiveness of foam sclerotherapy, endovenous laser ablation and surgery for varicose veins: results from the Comparison of LAser, Surgery and foam Sclerotherapy (CLASS) randomised controlled trial. Health Technol Assess. 2015 Apr; 19(27):1-342.

9. Burihan MC. Endovenous ablation (radiofrequency and laser) and foam sclerotherapy versus conventional surgery for great saphenous vein varices. Sao Paulo Med J. 2014; 132(1):69. [PubMed: 24474085]

10. Obi, AT., Sutzko, DC., Almeida, JI., Kabnick, L., Cronenwett, JL., Osborne, NH., et al. First 10month results of the Vascular Quality Initiative Varicose Vein Registry. J Vasc Surg Venous Lymphat Disord [Internet]. 2017. Available from: http://www.scopus.com/inward/record.url? eid=2-s2.0-85017564791\&partnerID=MN8TOARS

11. Sutzko DC, Andraska EA, Obi AT, Sadek M, Kabnick LS, Wakefield TW, et al. Age is not a barrier to good outcomes after varicose vein procedures. J Vasc Surg Venous Lymphat Disord. 2017; 5:647-657.e1. [PubMed: 28818215]

12. Pappas PJ, Lakhanpal S, Nguyen KQ, Vanjara R. The Center for Vein Restoration Study on presenting symptoms, treatment modalities, and outcomes in Medicare-eligible patients with chronic venous disorders. J Vasc surgery Venous Lymphat Disord. 2018 Jan; 6(1):13-24.

13. Barwell JR, Davies CE, Deacon J, Harvey K, Minor J, Sassano A, et al. Comparison of surgery and compression with compression alone in chronic venous ulceration (ESCHAR study): randomised controlled trial. Lancet (London, England). 2004 Jun; 363(9424):1854-9.

14. Raju S, Owen SJ, Neglen P. The clinical impact of iliac venous stents in the management of chronic venous insufficiency. J Vasc Surg. 2002 Jan; 35(1):8-15. [PubMed: 11802127]

15. Marston WA, Carlin RE, Passman MA, Farber MA, Keagy BA. Healing rates and cost efficacy of outpatient compression treatment for leg ulcers associated with venous insufficiency. J Vasc Surg. 1999 Sep; 30(3):491-8. [PubMed: 10477642]

16. Lin JC, Nerenz DR, Migliore P, Young R, Shepard AD, Weaver WD. Cost analysis of endovenous catheter ablation versus surgical stripping for treatment of superficial venous insufficiency and varicose vein disease. J Vasc surgery Venous Lymphat Disord. 2014 Jan; 2(1):98-103. 
17. Paty J, Elash CA, Turner-Bowker DM. Content Validity for the VVSymQ(R) Instrument: A New Patient-Reported Outcome Measure for the Assessment of Varicose Veins Symptoms. Patient. 2017 Feb; 10(1):51-63. [PubMed: 27384669]

18. Paty J, Turner-Bowker DM, Elash CA, Wright D. The VVSymQ(R) instrument: Use of a new patient-reported outcome measure for assessment of varicose vein symptoms. Phlebology. 2016 Aug; 31(7):481-8. [PubMed: 26183669]

19. Aber A, Poku E, Phillips P, Essat M, Buckley Woods H, Palfreyman S, et al. Systematic review of patient-reported outcome measures in patients with varicose veins. Br J Surg. 2017 Oct; 104(11): 1424-32. [PubMed: 28771700]

20. Romero PS, de Souza EN, Rodrigues J, Moraes MA. Changes in quality of life associated with surgical risk in elderly patients undergoing cardiac surgery. Int J Nurs Pract. 2015 Oct; 21(5):592_ 7. [PubMed: 24758233]

21. Mastracci TM, Hendren S, O'Connor B, McLeod RS. The impact of surgery for colorectal cancer on quality of life and functional status in the elderly. Dis Colon Rectum. 2006 Dec; 49(12):187884. [PubMed: 17036203]

22. Amemiya T, Oda K, Ando M, Kawamura T, Kitagawa Y, Okawa Y, et al. Activities of daily living and quality of life of elderly patients after elective surgery for gastric and colorectal cancers. Ann Surg. 2007 Aug; 246(2):222-8. [PubMed: 17667500]

23. McGirt MJ, Parker SL, Hilibrand A, Mummaneni P, Glassman SD, Devin CJ, et al. Lumbar Surgery in the Elderly Provides Significant Health Benefit in the US Health Care System: PatientReported Outcomes in 4370 Patients From the N2QOD Registry. Neurosurgery. 2015 Oct; 77(Suppl 4):S125-35. [PubMed: 26378350] 
Take Home Message

Complications of 12,262 varicose vein procedures were low in all age groups, including octogenarians, despite having more advanced venous disease at presentation.

Octogenarians had significant improvements in venous clinical severity scores and patient reported outcomes.

\section{Recommendation}

With good patient selection we recommend performance of indicated procedures for varicose veins in octogenarians. 


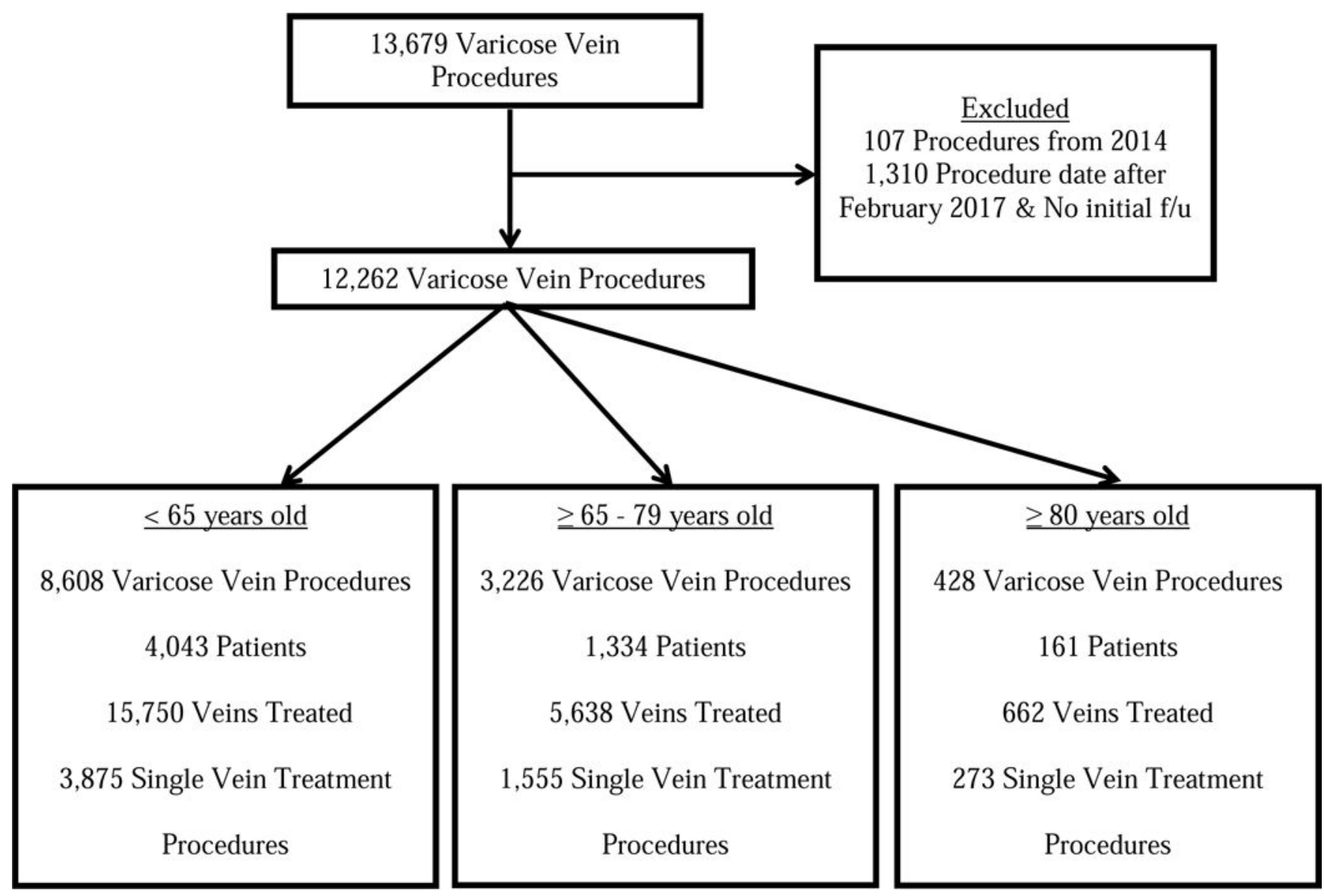

Figure 1.

Flow diagram of procedure breakdown in each age group. 
Pre Procedure CEAP Classification

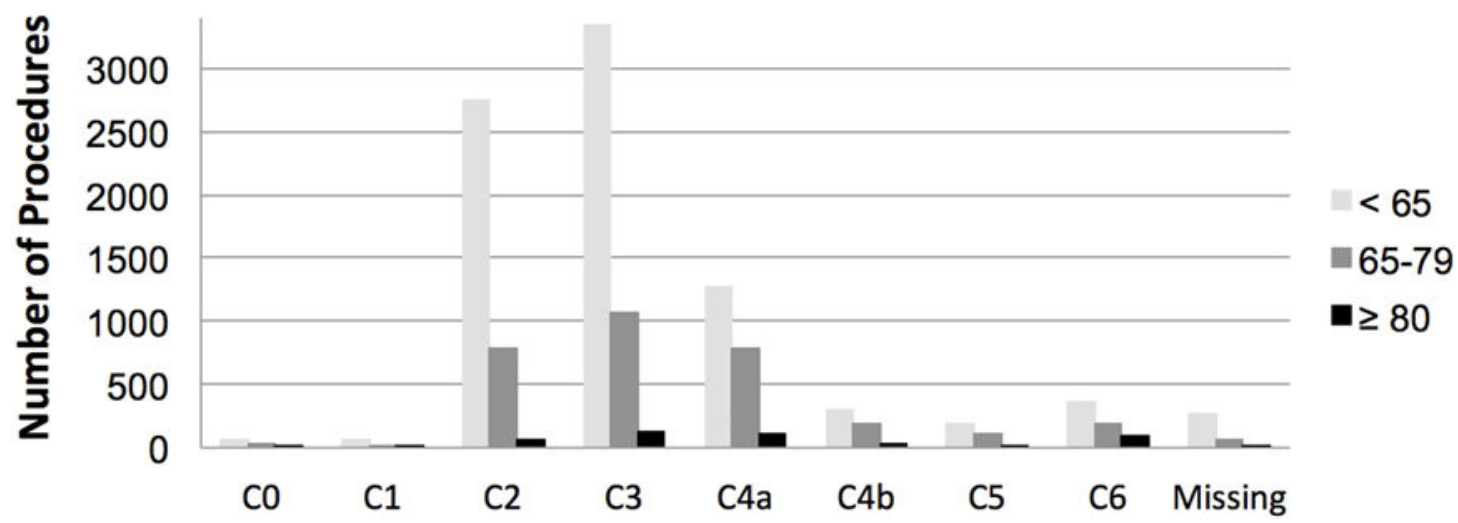

Figure 2.

Number of procedures performed for each pre procedure CEAP class within each age group. 

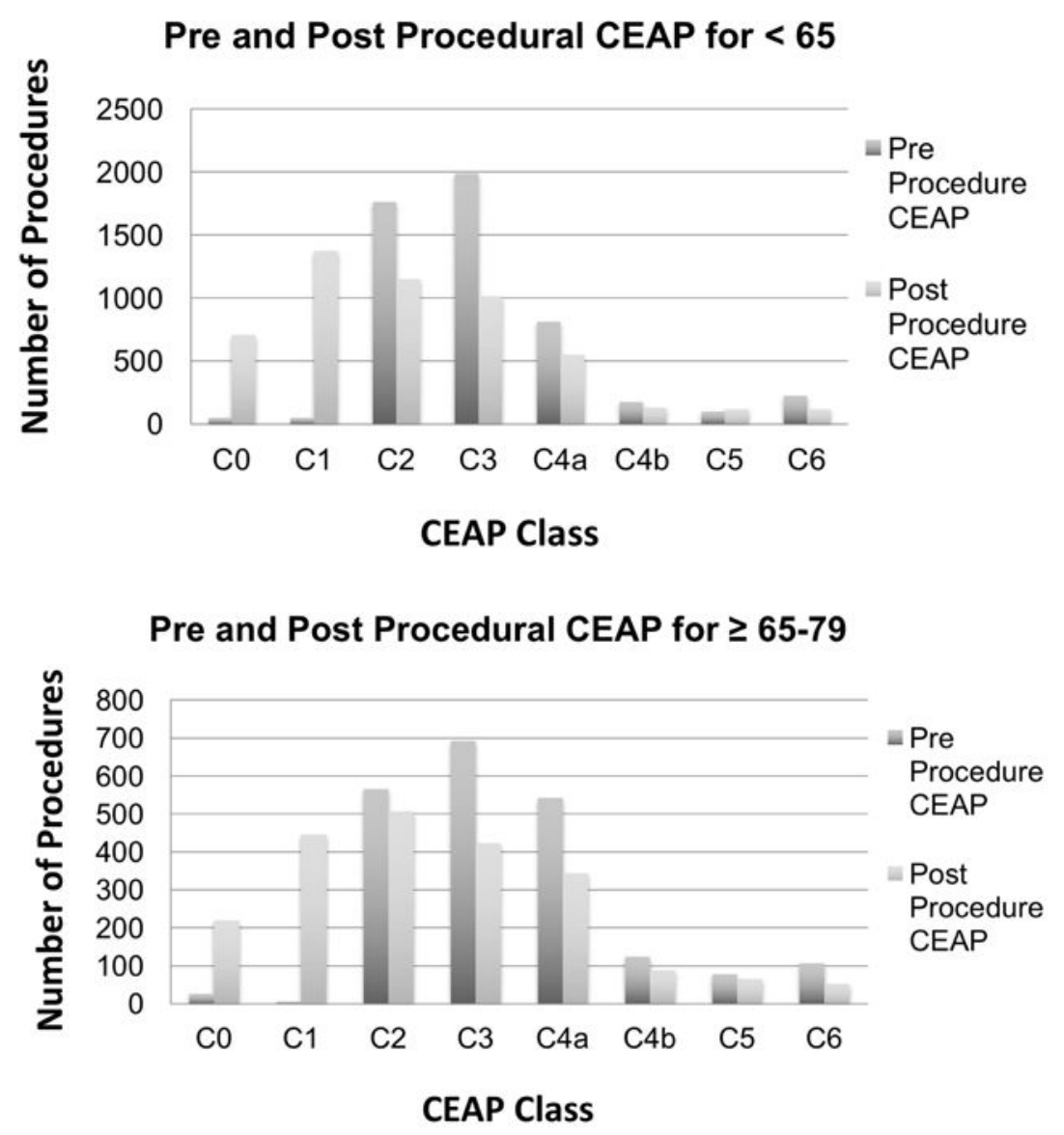

Pre and Post Procedural CEAP for $\geq 80$

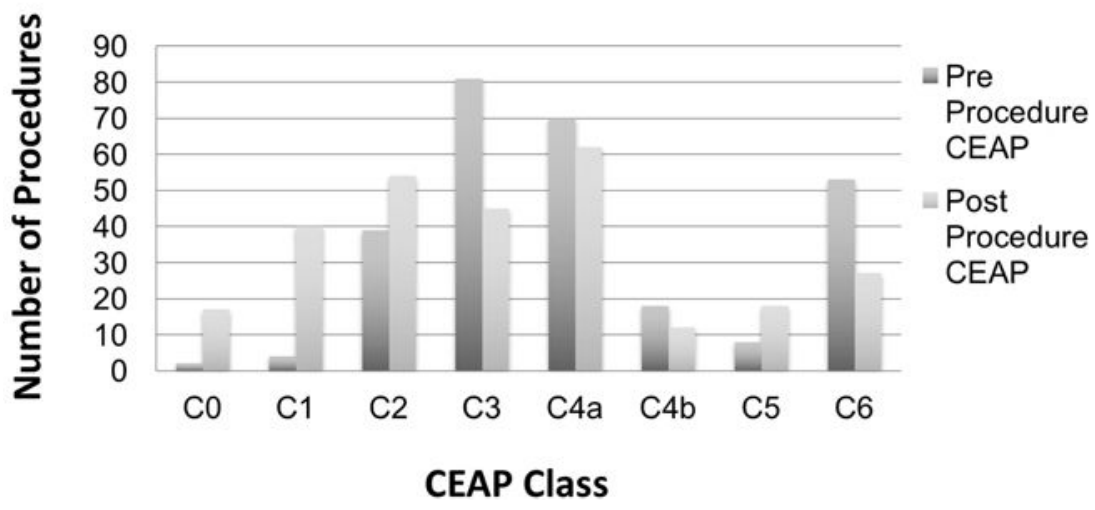

Figure 3.

A-C. Number of procedures performed for each pre procedure and post procedure CEAP class within each age group for all procedures with complete data. Post procedure CEAP was either from the 0-3 month or $>3$ month follow up visit, whichever is more recent. 


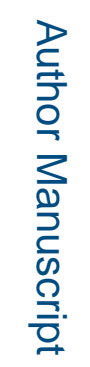

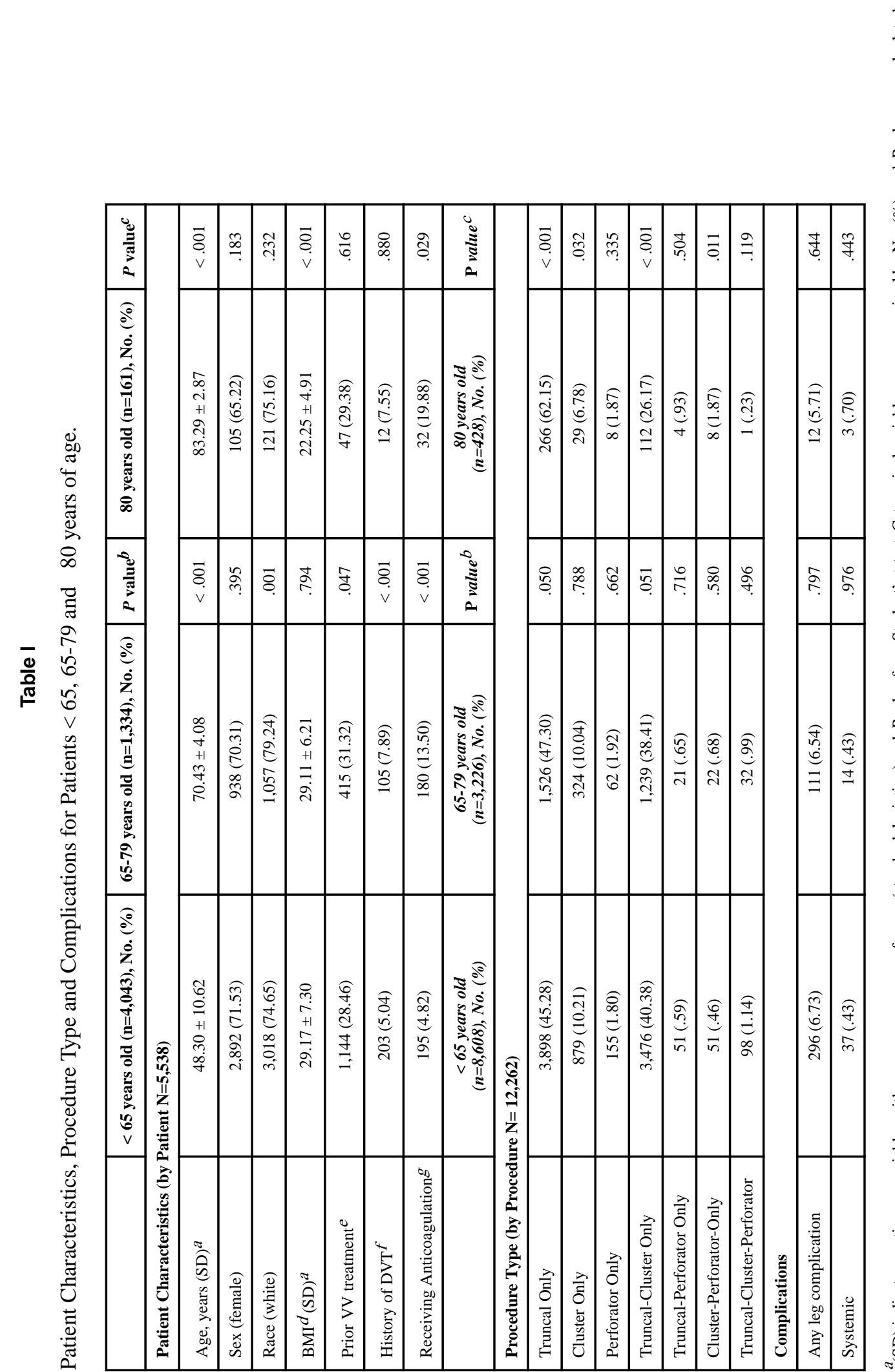



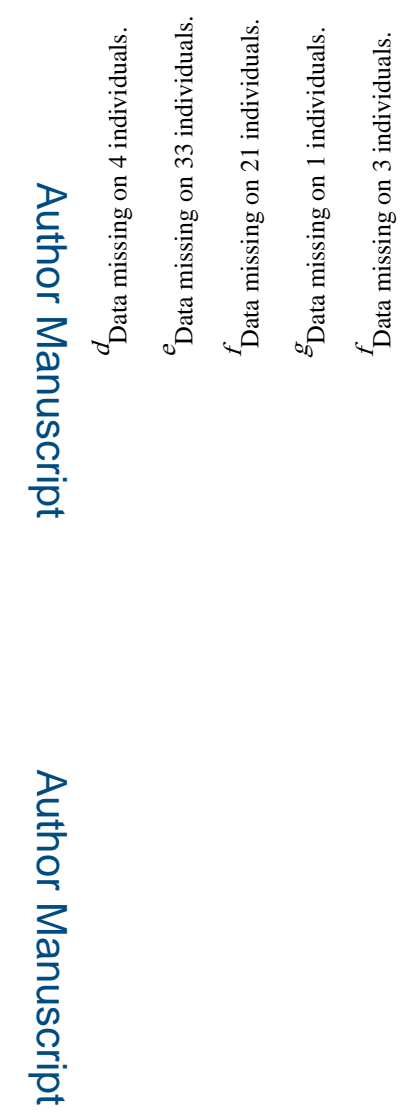

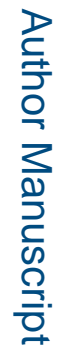

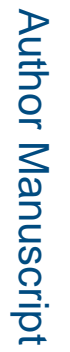

J Vasc Surg Venous Lymphat Disord. Author manuscript; available in PMC 2019 July 01. 
을
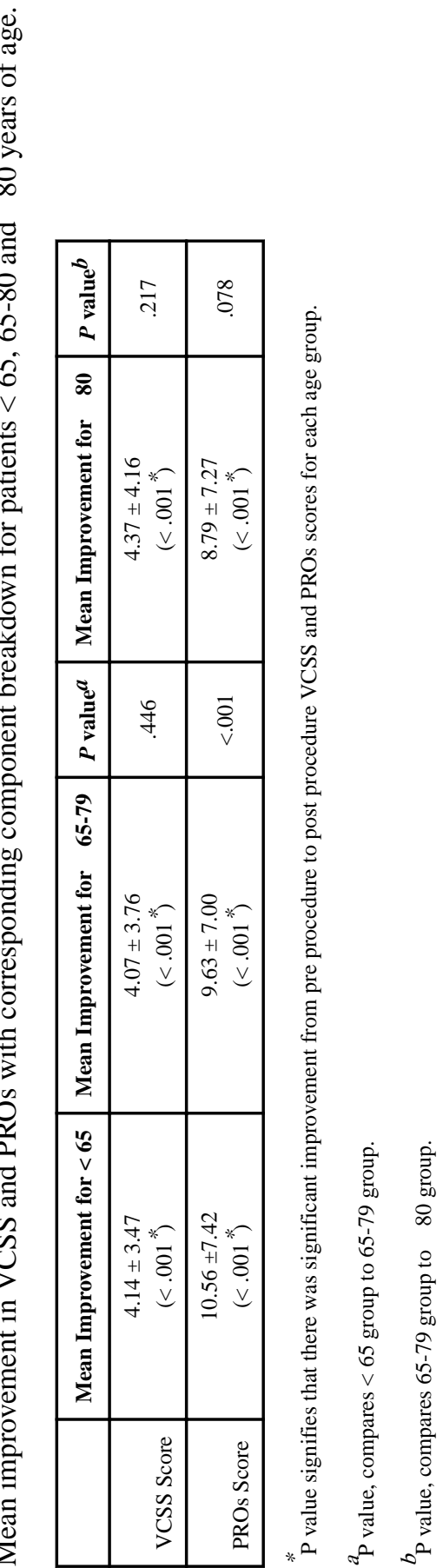

J Vasc Surg Venous Lymphat Disord. Author manuscript; available in PMC 2019 July 01. 